\title{
Use of Information Technology Resources under E-Youth Initiatives among University
}

\author{
Students \\ * Sonia Iram, PhD Scholar \\ ** Dr. Ijaz Ahmad Tatlah, Assistant Professor \\ *** Dr. Intzar Hussain Butt, Associate Professor
}

\begin{abstract}
This study seeks to find out the use of information technology resources (ITRs) among university students in Punjab. These ITRs were provided by the Government of Punjab as an initiative to equip the knowledge society with these latest tools. It was an initial step towards the advancement of technology assets in the National IT Policy Pakistan 2000. The study was quantitative. A crosssectional survey was conducted to collect the data. The target population was all the beneficiaries of e-youth initiatives at province Punjab. Convenient purposive sampling technique was used to collect the data. The sample of the study consisted of 76 beneficiaries of e-youth initiatives from the awarded universities. Analysis identified the use of information technology resources among the beneficiaries of e-youth initiatives. Results revealed that there is no significant difference in the usage of ITRs between male/female and hostelized/day scholar beneficiaries at the university level. All of them were utilizing ITRs under e-youth initiatives at the same level. Nowadays, information technology resources become very common for every student at the university level. Therefore, in the current scenario, there is a need to find out the impact of these information technology resources on academic performance and productivity of university students.
\end{abstract}

Keywords: E-youth initiative, information technology resources (ITR), university students

\section{Introduction}

The major portion of the world's population almost 1.8 billion comprised of youth aged 15 to 29 . This huge proportion can lead to a prosperous future of the nation but the fact is that they are going to be in trouble due to unemployment and uneven access towards resources (Secretariat, 2016). Youth is the social actor of change and progress (Walther, Stauber, \& Pohl, 2009). Technological literacy has become the requirement of society which the individuals must possess (Ritz, 2011). The New and emerging trends of technology brought about a significant effect on the lives of people, work and play (Jamil, Rafique \& Rizvi, 2014). For people, globalization is making the business world more accessible through which they can collaborate and operate across borders (Pennisi, 2012). Several countries are assisting their students in different ways of technological advancement (Kelly, 2013).

Information Technology (IT) leads anything to calculating machinery, such as networking, hardware, software, the Internet, or the people that work with these technologies (Productions, 2017). Information technology resources (ITR) are considered as hardware, software and communication equipment including personal computers, e-mail, internet, mobile or portable computers-laptop (Rouse \& Bigelow, 2015). These resources provide greater opportunities for accessing instruction and information by imparting into the curriculum. This equipment facilitate researchers and scholars and also to collaborate within and outside the institute (Cabinet, 2009; Mitchell, 2018; Sampath \& Kumar, 2010).

Considering the importance of technology in the academic activities of the students, the Government of the Punjab decided to facilitate the students with technological equipment. On the objective of this, some of the prominent schemes under this initiative: distribution of free laptops on the base of merit among students; establishment of e-libraries; e-Rozgar Centers; connection of Wi-Fi hotspots, IT Labs, e-Learn program and tablets in schools were initiated by the Government of Punjab (Policy, 2018). Among the above-mentioned initiatives taken by the Government of the Punjab Laptops Awards, e-libraries and Punjab WiFi hotspots were the concerned projects of the current

\footnotetext{
* University of Education, Lahore Email: soniairam2010@ yahoo.com

** University of Education, Lahore Email: tatlah@ue.edu.pk

*** University of Education, Lahore Email: $\underline{\text { ib@ue.edu.pk }}$
} 
study. The motivation and enthusiasm behind these initiatives was to assist students in acquiring knowledge and make them professionally excel (Center, 2017). The government spent millions of rupees on e-youth imitative to equip the knowledge society with technological advancements as prescribed in the National IT Policy Pakistan 2000 (Division, 2000). The government of the Punjab took these initiatives to bridge the digital divide among various groups of the society and it remained the focused area of interest.

Laptops were distributed to talented students at school, college and university levels under this initiative. It was proposed that these laptops would enable students to do their work when and where ever they want. Four successful phases were run by the Government of the Punjab under this scheme for the financial years of 2012 to 2018 (Secretary, 2015; Policy, 2018). In each phase almost one lac laptops were distributed among those students who met the eligibility criteria (Aziz, 2014; Policy, 2018).

The Government of Punjab initiated the project of e-libraries in different cities around the province for the promotion of reading culture and trend of research. These libraries based on the objective to entertain readers, enhance the facility of online data (authorized books, magazines, ebooks, publications) and provide free online access for whom conducted research and restrictions free licensing material (Punjab G. o., 2018). These libraries run under a very well-organized system and built-in modern infrastructure as they were committed to providing open access to everyone. Short courses would be conducted for the guidance of users and for the public to make them aware of the importance of e-libraries (Correspondent O. , 2018; Raja, 2018).

Another initiative taken by Punjab Information and Technology Board (PITB) the installation of free WiFi connections at a larger number of places in Lahore. The aim behind this was to improve the free internet provision. This WiFi has been installed around the Lahore main places in which governmental organizations, bus and railway stations and other public areas are included (Kanwal, 2017). PITB restricted video streaming and downloading to retain the use of these facilities positive. These Punjab WiFi hotspots also launched in Multan and Rawalpindi (Gotest, 2018).

Perhaps various studies have been conducted on the use of IT resources through which some of them discussed by the researcher. Awwada, Ayesha and Awwad (2013) conducted a study and found that both academic and non-academic activities were effected by laptops. Studies by Sana, Weston and Cepeda (2013) and Fairlie and Robinson (2013) found that laptop hinder in effective learning of the students. Ghaznavi Keikha and Yaghoubi (2011) researched students revealed that information and communication technology has a significant effect on improving students' educational motivation, questioning, researching and good academic achievement. The effect was the same among male and female students demographic perspective.

Gokalp (2010) examined the effects of information technologies on students at the university level. The study revealed that the university students were quite positive about the use of information technologies. Chen and Peng (2006) found in their research, if knowledge seekers utilize internet resources for positive purposes so that they can get positive results in their academics. A numerous researches (Crews \& Feinberg, 2002; Crouch, 2001; Mohammed \& Al-Karaki, 2008; Odell, Korgen, Schumacher \& Delucchi 2000; Wen \& Tsai, 2006; Wainer et al., 2008; Wu \& Tsai, 2006) have been conducted to know the results of internet and their impacts on students' performance.

\section{Research Objectives and Hypothesis}

To study the significant gender wise difference, among university students towards the use of information technology resources under e-youth initiatives in terms of its Access/availability, Use of ICTs, Social Media and Discussion Forums Involvement the objectives with their respective hypotheses have been designed:

1. To find out the university students' usage of information technology resources under e-youth initiatives concerning their gender.

2. To find out the university students' usage of information technology resources under e-youth initiatives concerning their residency status.

To accomplish the above-mentioned objectives following hypothesis were made:

1. $\mathrm{H}_{01}$ : There is no significant difference between male and female university students' usage of information technology resources under e-youth initiatives.

2. $\mathrm{H}_{02}$ : There is no significant difference between hostelized and day scholar university students' usage of information technology resources under e-youth initiatives. 


\section{Research Methodology and Procedure}

This study used a quantitative approach and it was descriptive. All the laptop awardee university students all over the Punjab were the target population of the study. The sample of the study was selected conveniently by using Google Survey Form. For the collection of data cross-sectional survey was employed to examine the use of information technology resources among university students. A part of a questionnaire developed by Das and Mishra in 2016 to measure learner use of technology was adapted by the researcher to find out the use of ITRs by university students, named e-Youth Initiative Survey (EYIS) (Kirkwood \& Price, 2016). The researcher created a Google Survey form to collect data which was responded by 76 beneficiaries of e-youth initiatives at the university level. The following table shows the detail of participated in university students:

Table No. 1

Participated Students' Universities detail

\begin{tabular}{clc}
\hline Sr. No. & University Name & No. of Students \\
\hline 1. & University of Education & 16 \\
2. & Punjab University & 13 \\
3. & Bahauddin Zakariya University & 7 \\
4. & Comsats Institute of Information Technology & 4 \\
5. & Govt. College University Faisalabad & 8 \\
6. & Lahore College for Women University & 6 \\
7. & University of Engineering and Technology & 5 \\
8. & Islamia University Bahawalpur & 5 \\
9. & University of Sargodha & 7 \\
10. & University of Gujrat & 5 \\
\hline Total & & 76 \\
\hline
\end{tabular}

The above table shows that students of 10 renowned universities of the Punjab have participated in this google survey form. The demographic variable of the questionnaire has consisted of gender and residency. The rest of the questionnaire had 24 items in total, the number of factors was four. Each factor had further statements which were varied in numbers. As the first factor was about 'Access of e-youth Initiatives' which was consisted of 5 statements, second 'Use of ICTs' containing 11 statements, third 'Social Media' comprising 4 statements and the fourth factor was about 'Mailing Lists and Discussion Forums' which was consisted of 4 statements. To find out the reliability of the questionnaire pilot study was conducted on 30 university students other than the sample of the study. The value of Cronbach's Alpha was .682.

\section{Finding and Analysis}

Researchers employed a t-test to find out the significant difference among university students' usage of information technology resources between male/female and hostelized/day scholars. Following are the description of the research findings presented in table 2 and 3 :

Table 2

Comparison of Male and Female Beneficiaries' usage of e-youth initiatives at the university level

\begin{tabular}{lllllll}
\hline Gender & $\mathrm{N}$ & Mean & SD & df & t & Sig. \\
\hline Male & 35 & 65.51 & 11.71 & 74 & .481 & .632 \\
Female & 41 & 64.36 & 9.11 & & & \\
\hline
\end{tabular}

In the above table independent sample t-test was run to find out the mean score difference between male and female beneficiaries' usage of ITRs under e-youth initiatives at the university level. The mean score of male students was 65.51 which is almost indistinguishable to the mean score of female students that was $64.36, \mathrm{t}(74)=.481, \mathrm{p}>.05$. Results revealed that there is no significant difference between the scores of male and female beneficiaries' usage of ITRs at the university level. So the first null hypothesis " $\mathrm{H}_{01}$ : There is no significant difference between male and female university students' usage of information technology resources under e-youth initiatives" is failed to reject. 
Table 3

Comparison of Hostelized and Day Scholar Beneficiaries' usage of e-youth initiatives at the university level

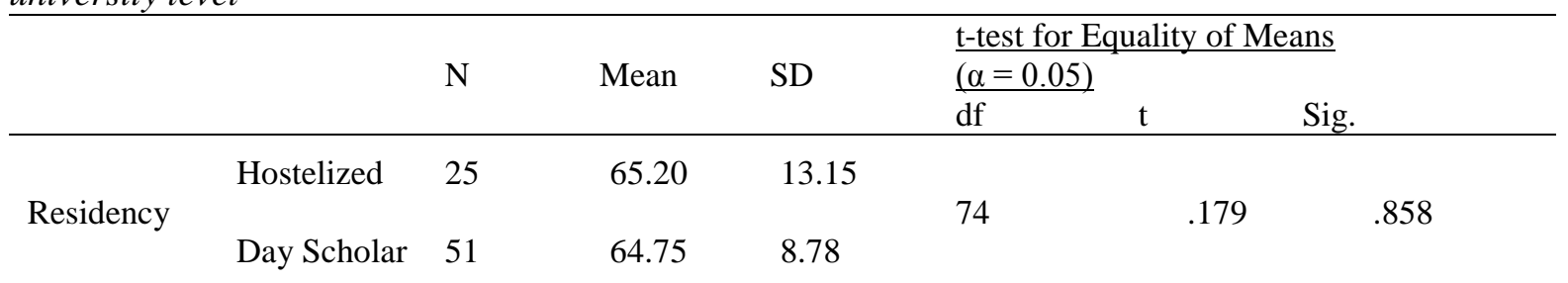

Table no. 3 depicts the independent sample t-test which was employed to measure the mean score difference between hostelized and day scholar beneficiaries' usage of ITRs under e-youth initiatives at the university level.

The mean score of hostelized 65.20 which is almost equal to mean score of day scholars that was $64.75, \mathrm{t}(74)=.179, \mathrm{p}>.05$. It shows that there is no significant difference between both hostelized and day scholar beneficiaries' usage of ITRs under e-youth initiatives at the university level. Hence the second null hypothesis, " $\mathrm{H}_{02}$ : There is no significant difference between hostelized and day scholar university students' usage of information technology resources under e-youth initiatives" was also failed to reject.

\section{Conclusion and Discussion}

Before the launching of e-youth initiatives students faced difficulties to approach the information technology resources to accomplish their academic tasks. Whom didn't have their laptops (computers) did not have frequent access to these resources, they can only use it in the working hours of the university. For the completion of their assignments and research projects they had to experience hurdles not to have these resources. The purpose behind e-youth initiatives was to bridge the digital gap to improve the learning of students and quality of education in the country and easy access towards IT recourses (Center, 2017). The findings of the present study which was conducted to measure the usage difference of information technology resources among the beneficiaries of e-youth initiatives showed that there was no significant difference in the usage of ITRs regarding both male and female and hostelized and day scholar university students. Somewhat supported by some certain studies conducted internationally in different countries that both male/female and hostelized/day scholars equally utilizing all the information technology resources either for academic and nonacademic purposes (Ghaznavi, Keikha, \& Yaghoubi, 2011; Kay, 2012; Verma \& Dahiya, 2016).

The results of the study showed that there is a frequent use of ITR among university students provided by the Government of the Punjab under the e-youth initiative. Gokalp (2010) examined the effects of information technology resources on university students. The study revealed that the university students were quite positive about the use of information technology resources.

\section{Recommendation}

The current study was just limited to find out the difference in the usage of information technology resources among university students. While keeping in view the increasing trends there is a need to explore the impact of these information technology resources on academic performance and productivity of university students.

\section{References}

Awwada, F., Ayesha, A., \& Awwad, S. (2013). Are Laptops Distracting Educational Tools in Classrooms? Social and Behavioral Sciences, 103, 154 - 160.

Aziz, U. (2014). Audit exposes mega scam in the PML-N laptop scheme.

Retrieved from pakistantoday.com.pk: https://www.pakistantoday.com.pk/2014/08/30/audit-exposesmega-scam-in-pml-n-laptop-scheme/

Cabinet, P. (2009). Responsible use of Information Technology Resources. Retrieved from Millersville University: https://www.millersville.edu/pfru.php

Center, I. (2017). Comsats. Retrieved from Comsats Website: http://sahiwal.comsats.edu.pk/ Primeministerlaptopscheme.aspx

Chen, Y.-F., \& Peng, S. S. (2008). University students' Internet use and its relationships with academic performance, interpersonal relationships, psychosocial adjustment, and selfevaluation... Cyberpsychology \& Behavior, 11, 467-469. 
Correspondent, O. (2018). LCWU inaugurates the digital library for research. Retrieved from https://tribune.com.pk/story/1610664/1-lcwu-inaugurates-digital-library-research/

Crews, M., \& Feinberg, M. (2002). Perceptions of university students regarding the digital divide. Social Science Computer Review, 20, 116-123.

Crouch, M. A. (2001). Using the Internet to facilitate student learning in a large therapeutics course: A three-year perspective. American Journal of Pharmaceutical Education, 65 (1), 7-12.

Fairlie, R. W., \& Robinson, J. (2013). Experimental evidence on the effects of home computers on academic achievement among schoolchildren. American Economic Journal: Applied Economics, 5 (3), 211-236.

Ghaznavi, M. R., Keikha, A., \& Yaghoubi, N.-M. (2011). The Impact of Information and Communication Technology (ICT) on Educational Improvement. International Education Studies, 4 (2), 116-125.

Gokalp, M. (2010). A study on the effects of information technologies on university students. Social and Behavioral Sciences, 9, 501-506.

Gotest. (2018). CM Punjab free wifi hotspot program 2018 complete information. Retrieved from https://gotest.pk/education/news/cm-punjab-free-wifi-hotspot/

IT \& Telecommunications Division. (2000). IT Policy and Action Plan. Islamabad: IT \& Telecommunications Division Ministry of Science \& Technology Government of Pakistan Islamabad.

Jamil, A., Rafique, F., \& Rizvi, S. (2014). Evaluating the Impact of IT on University Students of Bahawalpur with Special Reference to Free laptop Distribution by Govt. of Punjab. International Journal of Academic Research in Business and Social Sciences, 4 (6), 233-250.

Kanwal, M. (2017). PITB launches about 250 free WiFi hotspots. Retrieved from https://www.techjuice.pk/pitb-launches-about-250-free-wifi-hotspots/

Kay, R. H. (2012). Exploring the use of laptops in higher education: an analysis of benefits and distractions... E-Learn: World Conference on E-Learning in Corporate, Government, Healthcare, and Higher Education (pp. 630-635). Montreal: Association for the Advancement of Computing in Education (AACE).

Kelly, A. (2013). Technology can empower children in developing countries - if it's done right. Retrieved from The Guardian: https://www.theguardian.com/sustainable-business/ technology-empower-children-developing-countries

Kirkwood, A., \& Price, L. (2016). Technology-enabled learning implementation handbook. Burnaby: Commonwealth of Learning.

Mitchell, B. (2018). Lifewire. Retrieved from Lifewire.com: https://www.lifewire.com/introductioninformation-technology-817815

Mohammed, J., \& Al-Karaki, J. (2008). Integrating the Internet into Traditional Education: A Practical Study of University Students' Usage and Attitudes. International Arab Journal of Information Technology (IAJIT), 5 (3), 241-252.

Odell, P. M., Korgen, K. O., Schumacher, P., \& Delucchi, M. (2000). Internet use among female and male college students. CyberPsychology \& Behavior, 3 (5), 855-862.

Pennisi, E. (2012). The Current State of Globalization: How Connected is the World? Retrieved from Global Edge: https://globaledge.msu.edu/blog/post/1277/the-current-state-of-globalizationhow-c

Policy, P. I. (2018). Punjab IT Policy 2018. Lahore: Government of the Punjab.

Productions, S. (2017). TechTerms. Retrieved from TechTerms Website: https://techterms.com/ definition/it

Punjab, G. o. (2018). e-Library. Retrieved from https://elibrary.punjab.gov.pk/

Raja, E. (2018). Government of the Punjab To Set Up E-libraries To Promote Reading And Research Among Citizens. Retrieved from Government of the Punjab To Set Up E-libraries To Promote Reading And Research Among Citizens: https://blog.siasat.pk/punjab-governmentset-e-libraries-promote-reading-research-among-citizens/

Ritz, J. M. (2011). A Focus on Technological Literacy in Higher Education. The Journal of Technology Studies 37 (1), 333-344.

Sampath Kumar, B. T., \& Kumar, G. T. (2010). Perception and usage of e-resources and the internet by Indian academics. The electronic library, 28(1), 137-156. 
Sana, F., Weston, T., \& Cepeda, N. J. (2013). Laptop multitasking hinders classroom learning for both users and nearby peers. Computers \& Education, 62, 24-31.

Secretariat, C. (2016). Global Youth Development Index and Report 2016. United Kingdom: Commonwealth Secretariat.

Secretary, D. (2015, November 15). Invitation to Bid. Retrieved from https://hed.punjab.gov.pk/ system/files/Laptop_0.pdf

Rouse, M., \& Bigelow, S. J. (2015). Tech Target. Retrieved from Making the Agile development model current again: http://searchdatacenter.techtarget.com/definition/IT

Verma, C., \& Dahiya, S. (2016). Gender difference towards information and communication technology awareness in Indian universities. Springer Plus, 5 (1), 370-377.

Walther, A., Stauber, B., \& Pohl, A. (2009). UP 2 YOUTH. Youth - Actor of Social Change. Final Report. Tubingen: Creative Commons License.

Wen, M. L., \& Tsai, C.-C. (2006). University students' perceptions of and attitudes toward (online) peer assessment. Higher Education, 51 (1), 27-44.

Wu, Y.-T., \& Tsai, C.-C. (2006). University Students' Internet Attitudes and Internet Self-Efficacy: AStudy at Three Universities in Taiwan. Cyberpsychology \& behavior, 9 (4), 441-450. 